\title{
A comprehensive anticancer molecular study for genistein the promising anticancer drug
}

\author{
Rand R. Hafidh
}

Department of Microbiology, College of Medicine, University of Baghdad, Baghdad, Iraq.

Correspondence to Dr. Rand R. Hafidh (email: randriadh@comed.uobaghdad.edu.iq).

(Submitted: 25 May 2017 - Revised version received: 10 June 2017 - Accepted: 21 July 2017 - Published online: 26 September 2017)

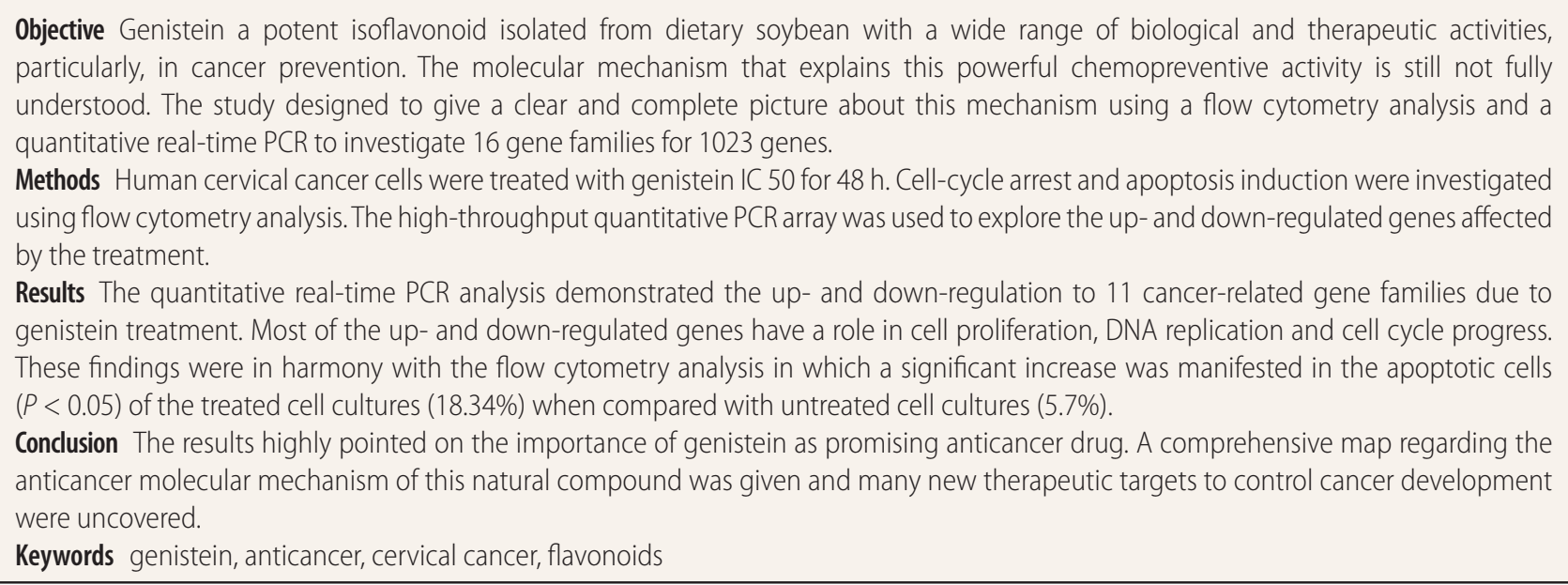

\section{Introduction}

The research to explore new anticancer compounds has become crucial with the increasing level of the carcinogenic and mutagenic substances in the environment. The side effects and emergence of chemotherapy-resistant cancer cells among patients have made cancer research and finding of new anticancer drugs from natural products particularly medicinal plants pivotal.

Genistein or 4',5,7-trihydroxyisoflavone, is a soybean isoflavone and a well-studied chemopreventive agent. It has been reported to potentiate the anticancer effect of some chemotherapeutics. Interestingly, it is well known for its ability to prevent cancer progression. ${ }^{2,3}$

Usually, the cervical cancer is one of the most diagnosed cancers and an important cause of mortality in women worldwide. Once cervical cancer has metastasized, patient outcome is poor. In contrast, it is fully treatable in the early stages. ${ }^{4}$ Recently, an important natural inhibitor of cancer metastasis; genistein, has emerged, which is widely distributed in beans. Moreover, diet with genistein; the bioactive molecule ("nutraceutical"), has been linked to reduce the rate of cancer metastasis in a number of population-based studies.,

The ability of genistein to stop metastasis and prompt apoptosis in cancer cells has been proved by several studies. Hence, genistein is able to lower mortality linked to solid organ cancer by important mechanisms., ${ }^{3,6}$ The ability to reduce the mortality associated with various cancer types, particularly cervical cancer is because this vital small molecule has a moderately extensive array of biological activities.

Recent studies have investigated the anticancer activity of genistein and found that this activity is due to its anti-inflammatory, antioxidant, induction of apoptosis, anti-angiogenesis, and anti-metastasis effect in addition to its action as immunomodulatory. ${ }^{7,8}$ On the other hand, studies with huge cancer genomics data that could explain genistein anticancer activity still not enough.

Therefore, this study was tried to look into the anticancer mechanism of genistein. By using high-throughput quantitative PCR array (WaferGen's SmartChip mRNA array), this study has explored 1023 genes related to 16 families. The study investigated the differences in the gene expression between treated and untreated cells. The distinctive aspect of this array in comparison to other microarrays is that the detected mRNAs is directly engaged in signaling pathways as well as cancer pathogenesis. Thus may have a role in the anticancer effect of genistein and tried to give a complete map for the target genes which up or down regulated by this product. This map will facilitate the understanding of the anticancer mechanism used by genistein and easiest the way to produce a new and cheap anticancer drug.

\section{Materials and Methods}

\section{Preparation of the Compound}

Genistein, from Glycine max (Soybean), 98\%, G6776-10MG, (Sigma) was prepared by dissolving in absolute dimethyl sulfoxide (DMSO), (BIO BASIC INC., NY, USA) and incubated at $-20^{\circ} \mathrm{C}$ as stock concentration $10 \mathrm{mg} / \mathrm{ml}$. The stock solution was diluted in $10 \%$ RPMI medium to give the working concentrations. The working concentrations $(15,30$, and $60 \mu \mathrm{g} / \mathrm{ml})$ were prepared freshly before each test. 


\section{Cancer Cell and Cytotoxicity Assay}

The cancer cell line, cervix adenocarcinoma cells (HeLa; ATCC CCL-2) was used to estimate the cytotoxic effects of Genistein. The MTS [3-(4,5 dimethylthiazol-2-yl)-5-(3-carboxymethoxyphenyl)-2(4-sulfophenyl)-2H-tetrazolium] colorimetric method (the Cell Titer 96 Aqueous One Solution Cell Proliferation Assay, Promega, USA) was used. It was used to decide the viable cells in proliferation or cytotoxicity assays. In each run, the experiment was repeated for three times with four wells per-working concentration. The absorbance was measured using a 96-well plate ELISA reader (Sunrise Basic Tecan, Grödig, Austria).

\section{Apoptosis Detection Methods}

\section{Flow Cytometry Analysis}

The level of cell apoptosis in the treated HeLa cells was investigated by using the concentration $(80 \mu \mathrm{g} / \mathrm{ml})$ of genistein that killed $50 \%$ of the cells (IC50). DNA staining solution $(500 \mu \mathrm{l})$ containing $25 \mu \mathrm{l}$ of propidium iodide (PI) $1 \mathrm{mg} / \mathrm{ml}$ (MP Biomedicals, LLC, IIIKrick, France), a double-stranded nucleic acid intercalating agent, and $50 \mu$ ribonuclease A from bovine pancrease ( $1 \mathrm{mg} / \mathrm{ml})$, (Sigma, Germany) in PBS was used to re-suspend the ice-cold ethanol fixed pellets. ${ }^{9}$ For each sample, the assay was measured in duplicate. CyAn ADP apparatus (BECKMAN COULTER, USA) was used to measure the propidium iodide fluorescence of individual nuclei. The flow cytometry results were analyzed by the software Summit (V4.3).

\section{SmartChip Real-Time PCR System}

The gene expression profiling of 4,128 reaction wells on a single sample was enabled by SmartChip Human Oncology Gene Panel Version 1.5.1 from (WaferGen, BIOSYSTEMS, Fremont, CA, U.S.A.) using the SmartChip Nanodispensere. The pre-optimized PCR primers that have been confirmed in both microliter- and nanoliter-scale SYBR Green real-time PCR experiments are already loaded in SmartChip panels. Quadruplicate primers of 1023 genes belonging to 16 functional groups was used (Table 1). Ten endogenous controls and six exogenous controls were used. The SmartChip Human Oncology Gene Panel was used to measure differential gene expression from $0.5 \mu \mathrm{g}$ of RNA of genistein treated HeLa cells vs. untreated cells, only significantly up- and down-regulated genes are displayed in this study.

\section{RNA Extraction}

The HeLa cell $\left(1 \times 10^{5}\right.$ cell/well $)$ with Roswell Park Memorial Institute-1640 (RPMI-1640) maintenance medium with or without genistein IC50 $(80 \mu \mathrm{g} / \mathrm{ml})$ was incubated in duplicate for 48 h. Total RNA was isolated using GF-1 kit (Vivantis Technologies, Malaysia).

RNA quality and quantity were determined by Life Science UV/Vis Spectrophotometer, DU Series 700 (BECKMAN COULTER, USA). RNA concentration used in downstream experiments was $546 \mathrm{ng} / \mu \mathrm{l}$. Moreover, total RNA quality was checked by Agilent 2100 Bioanalyzer (Agilent, USA) and RNA integrity number (RIN) was measured. RIN of total RNA was 8.5 and passed the quality control limit for running downstream experiments. The isolated RNA was stored at $-80^{\circ} \mathrm{C}$ and was ready for use in downstream application, namely, qRT-PCR.

\begin{tabular}{|c|c|}
\hline Gene family & Number of genes per family \\
\hline ADME* & 173 \\
\hline Apoptosis & 198 \\
\hline Cancer & 325 \\
\hline Cell cycle/proliferation & 52 \\
\hline Cardiovascular disease & 226 \\
\hline DNA damage repair & 36 \\
\hline Drug target & 43 \\
\hline G-protein coupled receptor & 31 \\
\hline Growth factor & 12 \\
\hline Homeostasis/metabolism & 9 \\
\hline Inflammation & 143 \\
\hline Kinase & 194 \\
\hline Proteinase & 11 \\
\hline Signal transduction & 303 \\
\hline Transcription factor & 95 \\
\hline Neurodisease/phosphatase & 10 \\
\hline
\end{tabular}

*Drug absorption, distribution, metabolism and elimination genes.

\section{Real-time Quantitative RT-PCR}

The reverse-transcription of $0.5 \mu \mathrm{g}$ of the isolated HeLa cell's RNA was done using iScript ${ }^{\mathrm{TM}} \mathrm{cDNA}$ Synthesis Kit (BIO-RAD, Hercules, Canadad). The isolated cDNA was stored at $-80^{\circ} \mathrm{C}$ for qRT-PCR reaction.

Real-time quantitative PCR reaction was conducted using the SmartChip which contains a 4128-nanowell array $(72 \times 72)$. These chips were preloaded with primer content optimized for performance with the SmartChip Real-Time PCR System. The SmartChip Nanodispenser was used to dispense the sample, combined with master mix and controls, under vacuum into the 5184-nanowell SmartChip. Five hundred (500) ng of starting sample yields the cDNA equivalent of $96 \mathrm{pg}$ of sample per well. Once loaded with sample, the SmartChip was placed into the WaferGen SmartChip Cycler. Each prepared sample undergoes 4,128 nano-scale real time polymerase chain reactions (RT-PCR) in parallel. The SmartChip real-time PCR system employs a qPCR reaction compatible with SYBR green I DNA-binding dye. Results were reported in the form of $\mathrm{C}_{t}$ (threshold cycles) and $\mathrm{T}_{\mathrm{m}}$ (melting temperatures) for amplicon-melting analyses. Forward and reverse primers for each gene were designed using bioinformatics tools.

Primers were selected based on criteria such as specificity, insensitivity to sequence polymorphisms, amplicon size, and minimization of primer artifacts. Primer specificity was determined using (a) melting curve analysis of amplicon product, (b) gel electrophoresis analysis of amplicons and (c) sequence verification of the amplicons. The up and down gene regulation was analyzed by SmartChip Software. The sensitivity of real-time PCR is 20-30 copies of RNA per well with specificity of genes discrimination $<90 \%$ homology. To keep precision of readings, standard deviation $<0.25 \mathrm{Ct}$ between replicates was 
used. For valid runs, all primers share the same Tm, amplicon size for each primer is either equal or close by, and no primer dimers or primer secondary structures are allowed. Thermal cycling of primers was $95^{\circ} \mathrm{C}$ for $180 \mathrm{~s}$ once, and for 40 cycles, $95^{\circ} \mathrm{C}$ for $60 \mathrm{~s}$, and $60^{\circ} \mathrm{C}$ for $70 \mathrm{~s}$ with amplicon size range 80-120 bp. Automatic screening for low-efficiency wells turned out to be zero and PCR efficiency for all primers was measured and taken into account for calculating fold changes in gene expression. Ten endogenous reference genes (TFRC-1, GAPDH-2, TAF-10, GUSB, TAF11, HPRT, PPIA, HMBS, $\mathrm{ACTB}$, and $\mathrm{B} 2 \mathrm{M})$; all-means normalization method, where the means of all expressed genes are employed, were used in the current study. In addition, six exogenous yeast controls were used (WGBS-YCF1-6); at least four exogenous controls, Yeast Control, were detected and were linear in proportion. At each run, two negative tissue controls (NTC), chip no. 34565 and 35935, and two tissue positive controls, brain tissue (PTC), chip no. 34576 and 35939, were used.

The fold change calculation used was based on the Comparative Ct Method. The Comparative Ct Method is also known as the $2^{-\Delta \Delta \mathrm{Ct}}$ Method and as follows: $\Delta \Delta \mathrm{Ct}=\Delta \mathrm{Ct}$ treated $-\Delta \mathrm{Ct}$ untreated, where: $\Delta \mathrm{Ct}$ treated $=\mathrm{Ct}$ treated $-\mathrm{All}$ Mean treated and $\Delta \mathrm{Ct}$ untreated $=\Delta \mathrm{Ct}$ untreated - All Mean untreated. The up-/down-regulated genes are those the genes that are at least two-fold change were considered as up-/ down-regulated.

\section{Data Analysis}

The current study showed data as mean \pm SD. SPSS software version (12.0.0.2) was used to analyse data. The confidence intervals (95\%) were used to evaluate the ability of the tested compound to inhibit the growth of the cells. The value of IC50 was calculated by linear regression index equations. Regarding flow cytomteric results, R2 fraction stand for sub-G apoptotic cells. In addition, the total cells minus apoptotic cells was calculated to get the cells' percentage at different cell cycle phases. For real-time qPCR, SmartChip qPCR software exerted all data analysis. Log up- or down-regulation of gene expression more than $2 \log$ was considered highly significant and was presented in this study. By using student $t$-test, $P$ values less than 0.05 were considered significant for the variations among percentages of apoptotic cells. a

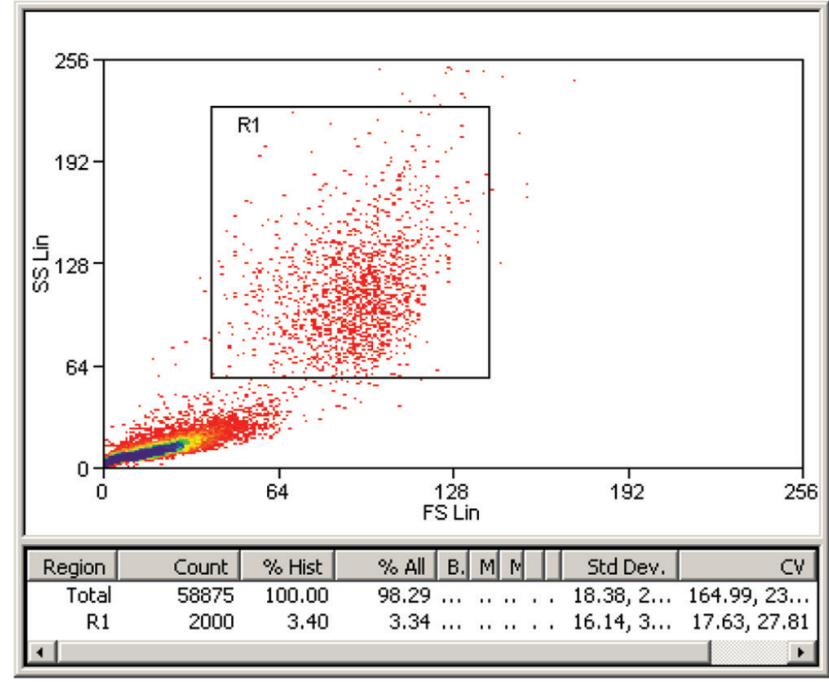

$\mathrm{b}$

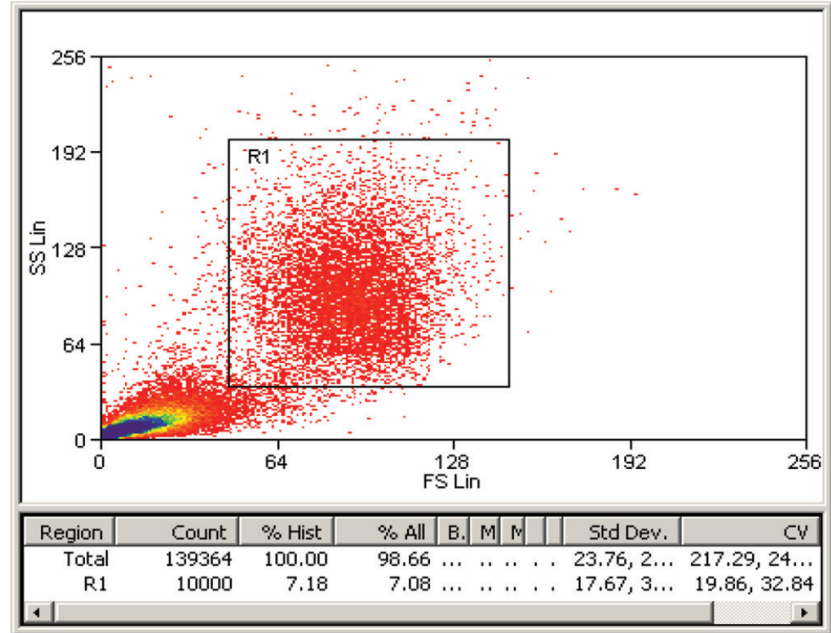

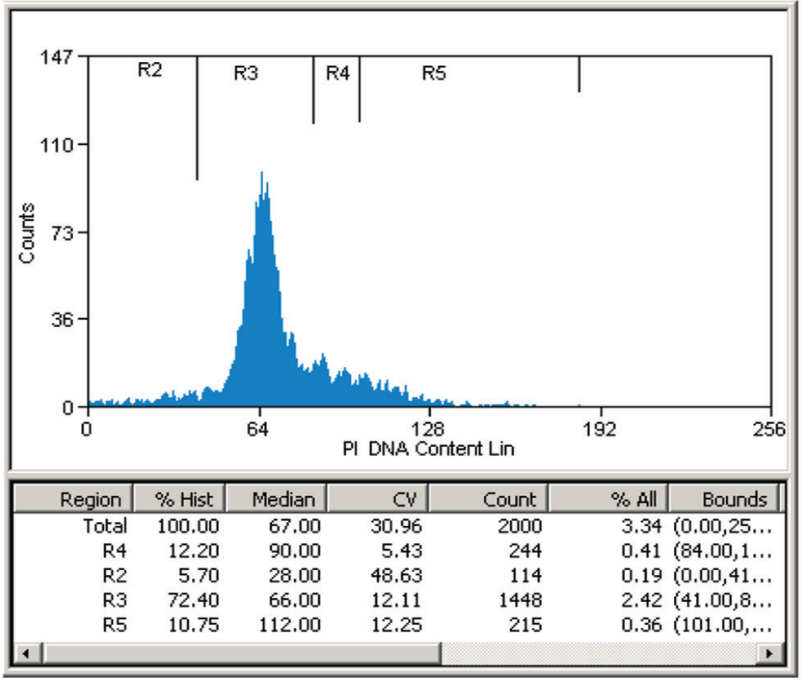

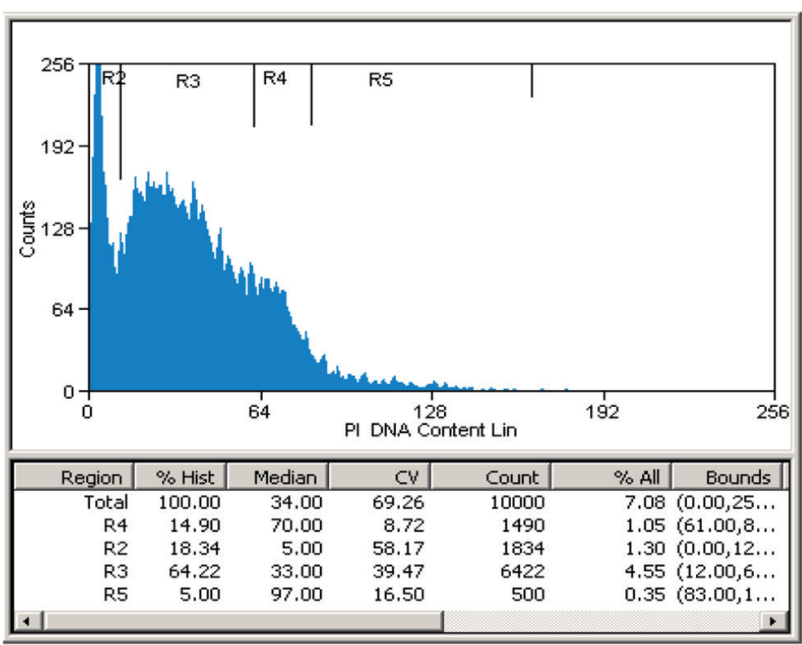

Fig. 1 The histograms represent DNA content frequency of HeLa cells after $48 \mathrm{~h}$ (a) untreated cultures (b) cultures treated with genistein IC50. The cell cycle distribution was affected by the treatment and apoptosis was induced. PI was used to stain the cells. CyAn ADP apparatus and Summit (V4.3) software were used to measure the fluorescence of the PI-stained cells. The estimated percentages of cells with fractional DNA content: apoptotic cells (R2), cells in G0/G1 (R3), S (R4), and G2/M (R5) phases of the cycle were provided by the software program. Total cell number (R1). 


\section{Results}

\section{The Cytotoxic Effect of Genistein on Hela Cells}

Genistein concentration that killed $50 \%$ of the cervix adenocarcinoma cells was $(80 \mu \mathrm{g} / \mathrm{ml})$. Later, this concentration was used to investigate the mechanism of the compound cytotoxicity by different techniques.

\section{Detection of Apoptosis by Flow Cytometry}

Flow cytometry was used to measure apoptosis in the HeLa cells treated with genistein and compared with untreated cells. Apoptosis was the type of cell death detected by flow cytometry after 48 -h treatment time. However, apoptosis was confirmed by integrating the results of both flow cytometry and RT-qPCR. A remarkable potential of genistein to induce apoptosis in the treated cells comparing to untreated cells was revealed by the flow cytometric analysis (Fig. 1). Hence, HeLa cells treated with genistein IC50 showed rise in the percentage of the apoptotic cells. The apoptotic cells increased significantly $(P<0.05)$ in the treated cell cultures (18.34\%) when compared with untreated cell cultures (5.7\%).

\section{Detection of the up- and Down-Regulation Gene Expression by SmartChip Real-Time PCR System}

The quantitative analysis by real-time PCR explained the anticancer mechanism of genistein. The treatment of HeLa cells with genistein for $48 \mathrm{~h}$ showed that 11 gene families from 16 total family groups integrated in the SmartChip Human Oncology Panel were affected by genistein. The treatment affected the family groups by clear up- and down-regulation to their genes (Table 2).

The gene family ADME showed two up-regulated genes and two down-regulated genes from total of 173 genes. The range was ( 4.05 to 2.34 ) with mean $3.19 \pm 1.21$ and ( -3.19 to $-5.57)$ mean $-4.38 \pm 1.68$ for the up- and down-regulation, respectively.

Apoptosis gene family revealed 2 and 3 up- and downregulated genes from total of 198 genes. The range was ( 4.05 to $2.34), 3.19 \pm 1.21$ and $(-3.41$ to -5.57$),-4.24 \pm 1.17$ for upand down-regulated genes, respectively.

The gene family signal transduction showed 3 and 6 from 303 genes of up- and down-regulated genes, respectively. With the range of $(4.05$ to 2.03$), 2.81 \pm 1.09$ for up-regulated genes and $(-2.46$ to -5.57$),-3.51 \pm 1.13$ for down-regulated genes.

From total of 325 genes of cancer family, one gene was up-regulated and two were down-regulated. The range was $(-2.17$ to -2.65$),-2.41 \pm 0.34$.

In the kinase family, the treatment revealed two down-regulated genes from 194 genes. The family genes' range was $(-2.56$ to -2.96$),-2.76 \pm 0.29$.

Cardiovascular disease family showed one up-regulated gene and four down-regulated genes from 226 genes. The genes' range was $(-2.03$ to -5.57$),-3.88 \pm 1.58$.

The up-regulated genes were two in transcription factor family while the down-regulated gene was only one from total of 95 genes. The range was (4.05 to 2.03), $3.04 \pm 1.43$.

The treatment caused up- and down-regulation to only one gene in the inflammation family genes from total of 143 .

\begin{tabular}{|c|c|c|}
\hline \multirow{2}{*}{$\begin{array}{l}\text { Gene family } \\
\text { ADME }\end{array}$} & \multicolumn{2}{|c|}{ Differentially expressed genes ${ }^{\log \text { change }}$} \\
\hline & Upregulated & DDIT3 ${ }^{4.05}, \mathrm{CDKN1} \mathrm{A}^{2.34}$ \\
\hline & Downregulated & 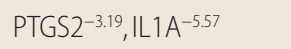 \\
\hline \multirow[t]{2}{*}{ Apoptosis } & Upregulated & DDIT3 ${ }^{4.05}$, CDKN1A $^{2.34}$ \\
\hline & Downregulated & $\begin{array}{l}\text { BNIP3L } L^{-3.41}, \mathrm{BCL}^{-3.72} \\
\text { IL1A }\end{array}$ \\
\hline \multirow[t]{2}{*}{ Signal transduction } & Upregulated & $\begin{array}{l}\text { DDIT3 } 4.05, \text { CDKN1A }{ }^{2.34}, \\
\text { EVI1 }^{2.03}\end{array}$ \\
\hline & Downregulated & 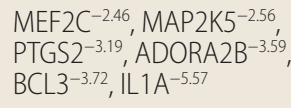 \\
\hline \multirow[t]{2}{*}{ Cancer } & Upregulated & CDKN1A $A^{2.34}$ \\
\hline & Downregulated & MKI67-2 ${ }^{-2.17}$, MLL3 $3^{-2.65}$ \\
\hline \multirow[t]{2}{*}{ Kinase } & Upregulated & \\
\hline & Downregulated & MAP2K- $^{-2.56}$, PDGFRL $^{-2.96}$ \\
\hline \multirow{2}{*}{$\begin{array}{l}\text { Cardiovascular } \\
\text { disease }\end{array}$} & Upregulated & CHI3L12.72 \\
\hline & Downregulated & $\begin{array}{l}\text { COL8A1-2.03, PTGS2-3.18, } \\
\text { ADAMTS1 } 1^{-4.75}, \text { IL1A }^{-5.57^{\prime}}\end{array}$ \\
\hline \multirow[t]{2}{*}{ Transcription factor } & Upregulated & DDIT3 $3^{4.05}, \mathrm{EVI} 1^{2.03}$ \\
\hline & Downregulated & MEF2C -2.45 \\
\hline \multirow[t]{2}{*}{ Inflammation } & Upregulated & CDKN1A ${ }^{2.34}$ \\
\hline & Downregulated & PTGS2-3.19 \\
\hline \multirow[t]{2}{*}{ DNA damage repair } & Upregulated & \\
\hline & Downregulated & $\mathrm{RPA}^{-2}{ }^{-2}, \mathrm{ATRX}^{-2.04}$ \\
\hline \multirow{2}{*}{$\begin{array}{l}\text { Cell cycle/ } \\
\text { proliferation }\end{array}$} & Upregulated & \\
\hline & Downregulated & $\mathrm{CCNF}^{-2.2}$ \\
\hline \multirow{2}{*}{$\begin{array}{l}\text { G-protein coupled } \\
\text { Receptor }\end{array}$} & Upregulated & \\
\hline & Downregulated & PDGFRL -2.96 \\
\hline
\end{tabular}

Genistein treatment for $48 \mathrm{~h}$ resulted in two downregulated genes from 36 genes of DNA damage repair family. The range of the down-regulated genes was ( -2 to -2.04$)$, $-2.02 \pm 0.03$.

One gene was down regulated in both cell cycle/proliferation family and G-protein coupled receptor family from their 52 and 31 genes, respectively.

On the other hand, there were minor changes in the expression of genes belong to drug target, homeostasis/metabolism and neurodisease/phosphatase families.

\section{Discussion}

It has been proved that natural products and their antioxidant components are the major source of human health promotion and maintenance. Hence, nature is still the perfect source for health promotion and for the supplementation of safe drugs. ${ }^{10}$ A potent antiviral and anticancer effect from beans or their sprout extracts have discovered by many studies. ${ }^{11,12}$ Furthermore, genistein, an isoflavone finds in many plants especially soybeans and fava beans proved to be highly effective anticancer compound. ${ }^{2,3,6}$ The results of this study have clarified the real anticancer mechanism of this highly promising anticancer drug, 
genistein. Also, the massive cancer genomic data of genistein anticancer activity were searched to facilitate the development of molecularly targeted cancer therapies. The function of the up- and down-regulated genes was synchronized with the increased percentage of apoptotic cells in treated HeLa cells (5.7-18.34\%), which investigated by a flow cytometry analysis.

Even though, the dramatic changes in ADME and apoptosis gene families were previously highlighted in many studies, ${ }^{13-15}$ a highlight on the genistein real mechanism of action was only given in this study. The results showed up-regulation to DNA damage inducible transcript 3 gene (DDIT3) by four families: ADME, apoptosis, signal transduction, and transcription factor. This is known as a protein-coding gene and has a critical role in the induction of apoptosis and cell cycle arrest. ${ }^{16}$ The study revealed number of down-regulated genes in many families like: cancer (2 genes), kinase (2 genes), and transcription factor (one genes). These results enhance other findings who found that genistein targets many pathways like caspases, B cell lymphoma 2 (Bcl-2, extracellular signal-regulated kinase $1 / 2$ (ERK1/2), kinesin-like protein 20A (KIF20A), nuclear transcription factor kappaB (NF-kappaB), inhibitor of NF-kappaB (IkappaB), wingless and integration 1 beta-catenin (Wnt/ beta-catenin), mitogen-activated protein kinase (MAPK) and phosphoinositide 3 kinase/Akt (PI3K/Akt) that can attribute to its anticancer therapeutic effect. ${ }^{17,18}$ In addition, the up-regulation to many important genes, which induce apoptosis following caspase activation was manifested in ADME, apoptosis, signal transduction, cancer and inflammation families. A gene with such function is cyclindependent kinase inhibitor 1A gene (CDKN1A). ${ }^{19}$

Similarly, the up-regulation to three genes in signal transduction family was in harmony with other previous studies. ${ }^{14,20}$ Most of these up-regulated genes have a role in the stimulation of apoptosis and cell cycle arrest. The down-regulation to six genes in the signal transduction family was the highest number among all the tested families. Although, the ability of genistein to down-regulate some of signal transduction family's genes was studied, ${ }^{20,21}$ a full map regarding signal transduction genes up- and down-regulation was clarified by this study.

From the down-regulated genes, which manifested after genistein treatment in DNA damage repair family were RPA1 (Replication Protein A1) and ATRX (ATRX, Chromatin Remodeler). These two protein-coding genes play an essential role in DNA replication. ${ }^{22,23}$ Moreover, only one gene was down-regulated in the cell cycle/proliferation family. It is an important regulator of cell cycle transitions, Cyclin F (CCNF), through its ability to activate and bind to cyclin-dependent protein kinases. ${ }^{24}$ Therefore, these down-regulated genes may suppress cancer development and could be a new therapeutic target for cancer control.

One of the important findings for this study is the downregulation to prostaglandin-endoperoxide synthase 2 gene (PTGS2). PTGS2 is a key step in the production of prostaglandin E2 (PGE2) in cancer cells, which plays important roles in modulating motility, proliferation and resistance to apoptosis. ${ }^{25}$ This down-regulation was found in ADME, signal transduction, cardiovascular disease and inflammation families.

The cardiovascular disease gene family showed one up-regulated gene and four down-regulated genes. The upregulated gene was Chitinase 3-Like 1, cartilage glycoprotein-39 (CHI3L1), which plays a role in inflammatory cell apoptosis, and tissue remodeling (the capacity of cells to respond to and cope with changes in their environment). ${ }^{26}$ Recently, CHI3L 1 gene found to be a good target to overcome some highly malignant diseases. ${ }^{27}$ In turn, the up-regulation to such target gene highlights the importance of our study and promotes further studies to explore the anticancer molecular mechanism of such promising drugs.

A protein-coding gene; PDGFRL (platelet-derived growth factor receptor like), which is highly expressed in human cervical cancer and associated with colorectal cancer, and hepatocellular carcinoma was down regulated after treatment. This gene belongs to $\mathrm{G}$ protein-coupled receptor family, known by its ability to regulate the cell proliferation of various cancers. ${ }^{28}$ So, it could be a good therapeutic target in controlling cancer cell proliferation.

\section{Conclusions}

Genistein, the soybean isoflavone, found to be a promising anticancer agent with a cheap and inexpressive source. This study gives a complete picture about the anticancer molecular mechanism of genistein by exploring 16 gene families and can be used as a good reference for future more specific studies on each gene family.

\section{Funding}

This research was conducted with the help of Universiti Putra Malaysia (UPM) to visiting scientists under grant no. U-1254-OS; UPM provided the bench work and covered research fees, while publication fees were not under financial cover.

\section{Conflict of Interest}

None

\section{References}

1. Hafidh RR, Abas F, Abdulamir AS, Jahanshiri F, Abu Bakar F, Sekawi Z a review: cancer research of natural products in Asia. Int J Canc Res. 2009;5:69-82

2. Xie X, Wang SS, Wong TC, Fung MC. Genistein promotes cell death of ethanol-stressed HeLa cells through the continuation of apoptosis or secondary necrosis. Cancer Cell Int. 2013;13:63.

3. Pavese JM, Farmer RL, Bergan RC. Inhibition of cancer cell invasion and metastasis by genistein. Cancer Metastasis Rev. 2010;29:465-482

4. Roomi MW, Cha J, Kalinovsky T, Roomi N, Niedzwiecki A, Rath M. Effect of a nutrient mixture on the localization of extracellular matrix proteins in HeLa human cervical cancer xenografts in female nude mice. Exp Ther Med. 2015;10:901-906.

5. McClements DJ, Xiao H. Designing food structure and composition to enhance nutraceutical bioactivity to support cancer inhibition. Semin Cancer Biol. 2017.

6. Dhandayuthapani S, Marimuthu P, Hormann V, Kumi-Diaka J, Rathinavelu A. Induction of apoptosis in HeLa cells via caspase activation by resveratrol and genistein. J Med Food. 2013;16:139-146.

7. Mohamed SIA, Jantan I, Haque MA. Naturally occurring immunomodulators with antitumor activity: an insight on their mechanisms of action. Int Immunopharmacol. 2017:50:291-304.

8. Tafrihi M, Nakhaei Sistani R. E-Cadherin/beta-catenin complex: a target for anticancer and antimetastasis plants/plant-derived compounds. Nutr Cancer. 2017;69:702-722. 
9. Siddik ZH. Checkpoint controls and targets in cancer therapy. Totowa, N.J.: Humana Press; 2010. xiv, p. 273.

10. Hafidh RR, Abdulamir AS, Abu Bakar F, Abas F, Jahanshiri F, Sekawi Z. Antioxidant research in Asia in the period from 2000-2008. Am J Pharmacol Toxicol. 2009;4:48-66.

11. Hafidh RR, Abdulamir AS, Bakar FA, Jalilian FA, Abas F, Sekawi Z. Novel molecular, cytotoxical, and immunological study on promising and selective anticancer activity of mung bean sprouts. BMC Complement Altern Med. 2012;12:208.

12. Hafidh RR, Abdulamir AS, Abu Bakar F, Sekawi Z, Jahansheri F, Jalilian FA Novel antiviral activity of mung bean sprouts against respiratory syncytial virus and herpes simplex virus -1: an in vitro study on virally infected Vero and MRC-5 cell lines. BMC Complement Altern Med. 2015;15:179.

13. Yang Z, Kulkarni K, Zhu W, Hu M. Bioavailability and pharmacokinetics of genistein: mechanistic studies on its ADME. Anticancer Agents Med Chem. 2012;12:1264-1280.

14. Chen J, Duan Y, Zhang X, Ye Y, Ge B. Genistein induces apoptosis by the inactivation of the IGF-1R/p-Akt signaling pathway in MCF-7 human breast cancer cells. Food Funct. 2015;6:995-1000.

15. Zhu J, Zhang C, Qing Y, Cheng Y, Jiang X, Li M, et al. Genistein induces apoptosis by stabilizing intracellular p53 protein through an APE1-mediated pathway. Free Radic Biol Med. 2015;86:209-218.

16. Liu X, Liu K, Qin J, Hao L, Li X, Liu Y, et al. C/EBPbeta promotes angiogenesis through secretion of IL-6, which is inhibited by genistein, in EGFRvIIIpositive glioblastoma. Int J Cancer. 2014;136:2524-2534.

17. Spagnuolo C, Russo GL, Orhan IE, Habtemariam S, Daglia M, Sureda A, et al. Genistein and cancer: current status, challenges, and future directions. Adv Nutr. 2015;6:408-419.

18. Dai W, Wang F, He L, Lin C, Wu S, Chen P, et al. Genistein inhibits hepatocellular carcinoma cell migration by reversing the epithelialmesenchymal transition: partial mediation by the transcription factor NFAT1. Mol Carcinog. 2013;54:301-311.
19. Yu GP, Xiao QY, Shi ZQ, Tang LS, Ma XP, Zhang LY, et al. Genetic polymorphisms in apoptosis-related genes and the prognosis of hepatocellular carcinoma. Am J Cancer Res. 2015;5:3249-3259.

20. Song M, Tian X, Lu M, Zhang X, Ma K, Lv Z, et al. Genistein exerts growth inhibition on human osteosarcoma MG-63 cells via PPARgamma pathway. Int J Oncol. 2015;46:1131-1140.

21. Whirledge S, Senbanjo LT, Cidlowski JA. Genistein disrupts glucocorticoid receptor signaling in human uterine endometrial Ishikawa cells. Environ Health Perspect. 2014;123:80-87.

22. Lin YL, Shivji MK, Chen C, Kolodner R, Wood RD, Dutta A. The evolutionarily conserved zinc finger motif in the largest subunit of human replication protein $A$ is required for DNA replication and mismatch repair but not for nucleotide excision repair. J Biol Chem. 1998;273:1453-1461.

23. Episkopou H, Draskovic I, Van Beneden A, Tilman G, Mattiussi M, Gobin $\mathrm{M}$, et al. Alternative lengthening of Telomeres is characterized by reduced compaction of telomeric chromatin. Nucleic Acids Res. 2014;42:4391-4405.

24. D'Angiolella V, Donato V, Forrester FM, Jeong YT, Pellacani C, Kudo Y, et al. Cyclin F-mediated degradation of ribonucleotide reductase $\mathrm{M} 2$ controls genome integrity and DNA repair. Cell. 2012;149:1023-1034.

25. Kim HB, Kim M, Park YS, Park I, Kim T, Yang SY, et al. Prostaglandin E2 Activates YAP and a positive-signaling loop to promote colon regeneration after colitis but also carcinogenesis in mice. Gastroenterology. 2017;152:616-630

26. Hamilton G, Rath B, Burghuber O. Chitinase-3-like-1/YKL-40 as marker of circulating tumor cells. Transl Lung Cancer Res. 2015;4:287-291.

27. Hamilton G, Rath B, Ulsperger E. How to target small cell lung cancer. Oncoscience. 2015;2:684-692.

28. Zhang Q, Wu YZ, Zhang YM, Ji XH, Hao Q. Activation of G-protein coupled estrogen receptor inhibits the proliferation of cervical cancer cells via sustained activation of ERK1/2. Cell Biochem Funct. 2015;33:134-142.

This work is licensed under a Creative Commons Attribution-NonCommercial 3.0 Unported License which allows users to read, copy, distribute and make derivative works for non-commercial purposes from the material, as long as the author of the original work is cited properly. 